Special Issue of the 6th International Congress \& Exhibition (APMAS2016), Maslak, Istanbul, Turkey, June 1-3, 2016

\title{
Prediction of Inner Grooved Circular Jet Flow with Artificial Neural Networks
}

\begin{abstract}
A.T. INAN*
Marmara University, Faculty of Technology, Dept. Mechanical Engineering, 34722 Istanbul, Turkey

In this study, an artificial neural network model was established by using experimental measurement values obtained from a low-speed subsonic wind tunnel, with the length of $75 \mathrm{~cm}$ and experiment test section of $32 \times 32 \mathrm{~cm}^{2}$. Model results were compared with experimental values and then, the prediction was made for the unmeasured tunnel stream values. In the wind tunnel, the jet velocity of $25 \mathrm{~m} / \mathrm{s}$ and four tunnel velocities of $0,5,10$ and $20 \mathrm{~m} / \mathrm{s}$ were used. At four measurement stations $x / D=0.3, x / D=12.5, x / D=31.2$ and $x / D=50$, experimental measurements were made using a hot wire anemometer. This study is the continuation of the work done by Inan and Sisman [T. Inan, T. Sisman, Acta Phys. Pol. A 127, 1145 (2015)]. Inner grooved circular jet flows at $x / D=0.3$ and $x / D=50$ stations with average tunnel flow velocities of $7.5 \mathrm{~m} / \mathrm{s}$ and $15 \mathrm{~m} / \mathrm{s}$ were studied by using artificial neural networks.
\end{abstract}

DOI: 10.12693 /APhysPolA.131.403

PACS/topics: 47.27.wg, 42.79.Ta

\section{Introduction}

Although there have been intensive experimental and computational studies on the structure of jet flows, the studies about inner grooved jet flows are new. This study is the contunuation of the work done by Inan and Sisman, where inner grooved circular pipe flows were studied experimentally and numerically [1].

Many researchers have used ANN method in their studies. Chawla et al. [2] have carried out the design and testing of power plant and power control systems by using ANN. Gulez et al. [3] have protected electrical and electronic equipment from excessive current by using ANN. Sarikas et al. [4] have diagnosed thyroid gland disease by using fuzzy logic and neural networks. Kesen, Yayla and Yildirim [5] have made an educational simulator. In another study, they have also made an evaluation of a product development performance by using ANN [6]. Dogmus et al. [7] have used ANN in the control of relative humidity. Ekmekci et al. [8] have used ANN circular jet flows and estimated velocity values at non-measured stations.
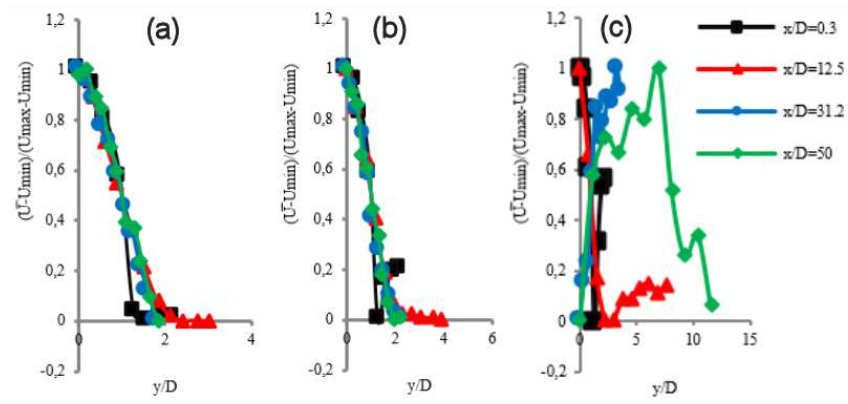

Fig. 1. Dimensionless velocity distributions for inner grooved circular tube for $25 \mathrm{~m} / \mathrm{s}$ jet velocity, for tunnel velocity of (a) $5 \mathrm{~m} / \mathrm{s}$, (b) $10 \mathrm{~m} / \mathrm{s}$ and (c) $20 \mathrm{~m} / \mathrm{s} \mathrm{[9].}$

*e-mail: ainan@marmara.edu.tr
In the ANN model, tunnel velocities, length ratios and radial distances were taken as input. Network was constructed and modeling was made using these data. Then the relevant radial velocity distribution was obtained as the output. Using the data obtained from this network, mean velocity values at $7.5 \mathrm{~m} / \mathrm{s}$ tunnel velocities were predicted. Dimensionless velocity distributions at these intervals are shown in Fig. 1.

\section{Experimental method}

Experimental studies were performed in the subsonic air tunnel designed and constructed by Inan [10]. To obtain a jet flow, a secondary air generator was used, as shown in Fig. 2 [1]. An inner grooved copper tube having length of $1.2 \mathrm{~m}$ and inner diameter of $16 \mathrm{~mm}$ was used for measurement of the jet. Features of inner grooved tube are given in Fig. 3 and the layout of the experimental set-up is shown in Fig. 2.

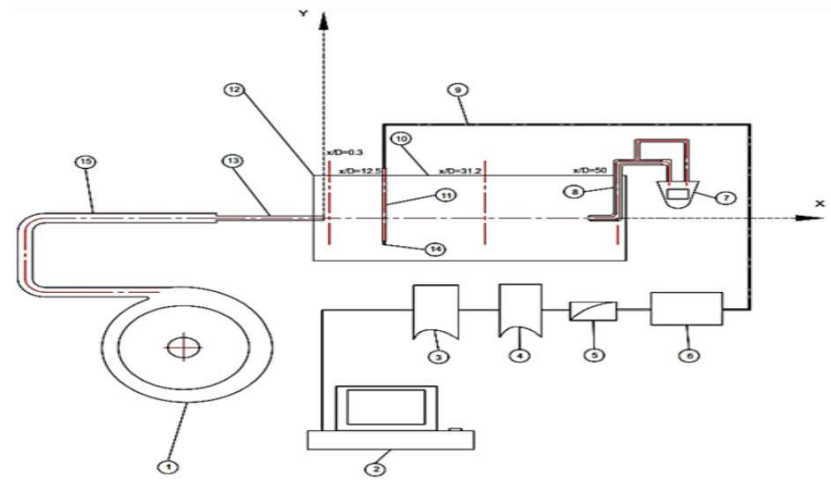

Fig. 2. Layout of experimental setup. 1. Jet air generator, 2. computer, 3. data analysis element, 4. time series, 5. linearization, 6 . Wheatstone bridge and servo amplifier, 7. digital Pitot static tube screen, 8. Pitot tube, 9. coaxial cable, 10. experimental chamber, 11. probe support, 12 . wind tunnel experimental chamber inlet, 13 . jet tube element, 14 . probe, 15 . tube connection element. 


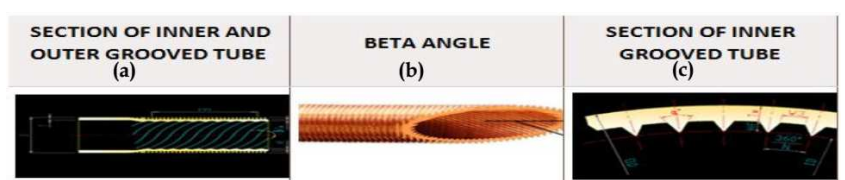

Fig. 3. Inner grooved circular tube, (a) section of inner and outer grooved tube, (b) beta angle, (c) section of inner grooved tube [1].

Using the data obtained from the measurements, dimensionless flow profiles and velocity distributions for $25 \mathrm{~m} / \mathrm{s}$ jet velocity were plotted, as shown in Fig. 1, for (a) $5 \mathrm{~m} / \mathrm{s}$, (b) $10 \mathrm{~m} / \mathrm{s}$, (c) $20 \mathrm{~m} / \mathrm{s}$.

\subsection{ANN method}

In this study ANN model with multi-layered forward feedback propagation was used $[2,3]$. The main reason for using multilayered feed-forward back propagation ANN model [4] is that this is a globally recognized approximation and considering the available data this model is the best in terms of performance among ANN models [11]. ANN is made of layers. In this ANN model, 50 neurons are defined in the hidden layer and one neuron in the exit layer. Tunnel velocity, length, ratio and radial distances are defined as inputs. ANN structure is shown in Fig. 4.

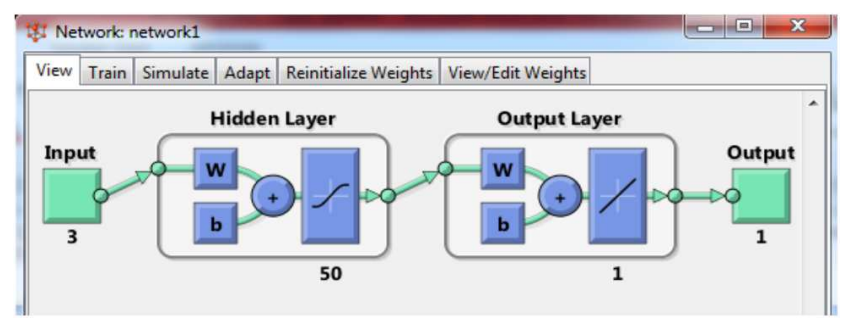

Fig. 4. The structure of ANN.

In ANN, learning algorithms are used to instruct the network. In this study adaptive Levenberg Marquardt algorithm of training has been used for its simplicity and high performance rates.

The following scheme shows gradient descent with momentum (Fig. 5a) used in the training of ANN model, testing and validation data (Fig. 5b) and finally the mean squared error (MSE) (Fig. 5c) of ANN model.

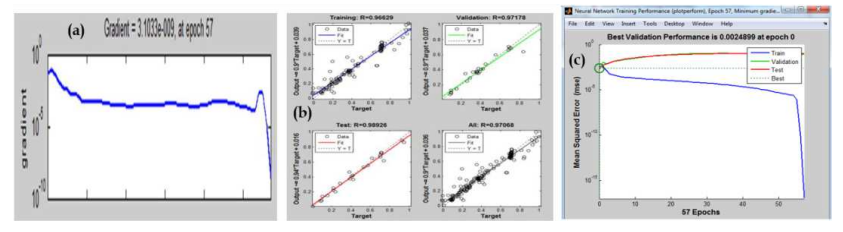

Fig. 5. (a) Gradient descent with momentum used in the training of ANN model, (b) testing and validation data for performance values used in the training of ANN model, (c) mean squared error (MSE) of ANN model.
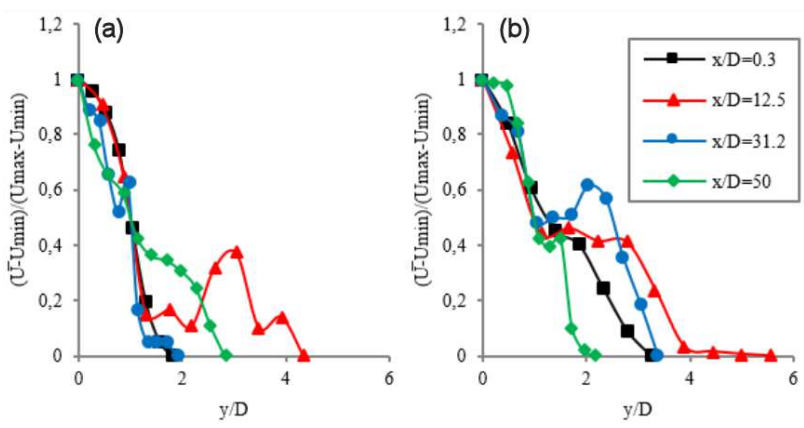

Fig. 6. Dimensionless velocity distributions for inner grooved circular tube for $25 \mathrm{~m} / \mathrm{s}$ jet velocity, for tunnel velocities of (a) $7.5 \mathrm{~m} / \mathrm{s}$, (b) $15 \mathrm{~m} / \mathrm{s}$.

ANN model is instructed at $97 \%$ and it confirms obtained experimental data in $98 \%$, as seen in Fig. 5 for 7.5 and $15 \mathrm{~m} / \mathrm{s}$ tunnel velocities, where experimental measurements were not performed. Dimensionless velocity distributions obtained by ANN are given in Fig. 6 .

\section{Results and discussion}

For the inner grooved circular tubes, jet flow measurements were performed under the conditions with the tunnel flow velocity of $5 \mathrm{~m} / \mathrm{s}, 10 \mathrm{~m} / \mathrm{s}$ and $20 \mathrm{~m} / \mathrm{s}$ and jet flow velocity of $25 \mathrm{~m} / \mathrm{s}$. The obtained plots are presented in Fig. 1.

Since the turbulence density of tunnel was between $0.7 \%$ and $0.4 \%$, the tunnel was found to be suitable as the experimental chamber [10]. Four measurement stations $(x / D=0.3, x / D=12.5, x / D=31.2$ and $x / D=50)$ were defined inside the experimental chamber for jet flow measurements. The measurements were taken vertically from the predetermined points.

In this study, the velocity values given in dimensionless plots at the predetermined intervals were predicted using ANN for the tunnel velocities of $7.5 \mathrm{~m} / \mathrm{s}$ and $15 \mathrm{~m} / \mathrm{s}$. The predicted average velocity values are then given in Fig. 6 as dimensionless plots.

It can be seen from the dimensionless plots, that when the tunnel velocity was $7.5 \mathrm{~m} / \mathrm{s}$ jet flow retained its structure at the $x / D=0.3$ and $x / D=12.5$ measurement stations. At the measurement station $x / D=12.5$, it was observed that for the measurements deviating from the $y$ axis, the jet structure was lost within the tunnel. At the measurement stations $x / D=31.2$ and $x / D=50$, the jet flow structure was completely lost within the tunnel. This led to the fluctuations on the plots, which have been caused by the presence of inner grooved pipes. The tunnel flow was then stabilized.

When the tunnel velocity was $15 \mathrm{~m} / \mathrm{s}$ in the dimensionless graphs, the jet flow structure was completely retained at the $x / D=0.3$ and $x / D=12.5$ measurement stations. But just after the measurement station $x / D=31.2$, the jet flow structure started to loss and this loss continued at the $x / D=50$ measurement station. In the end jet flow was replaced by tunnel flow. It was observed that the turbulence has formed for axially measured velocities at $x / D=31.2$ and at $x / D=50$ stations. 
When the ratio between tunnel velocity and jet velocity become higher, the jet flow structure was lost in a short time. On the other hand, when the ratio between tunnel velocity and jet velocity become smaller, jet flow structure has retained partly. From the comparison of both graphics (ANN and experimental) for the minimum and maximum values, it was found that core, transition and turbulence regions were present in both investigations. It was observed that predictions obtained by ANN were in agreement with experimental data.

\section{References}

[1] T. Inan, T. Sisman, Acta Phys. Pol. A 127, 1145 (2015).

[2] G. Chawla, M.S. Sachdev, G. Ramakrishna, Power Plants and Power Systems Control, Kananaskis, Canada 2006.

[3] K. Gulez, R. Yumurtaci, M. Uzunoglu, in: Proc. 6th Int. Conf. OPTIM'98, IEEE, Brasov 1998.
[4] A. Sarikas, E. Canayaz, U. Kesen, in: 2nd Int. Symp. Innovative Technologies in Engineering and Science (ISITES 2014) Karabuk, Turkey 2014, p. 715.

[5] U. Kesen, T. Yildirim, in: Proc.15th Int. Symp. on Computer and Information Sciences (ISCIS XV), Istanbul, Turkey 2000, p. 545.

[6] U. Kesen, Y. Yayla, T. Yildirim, in: Akıllı Sistemlerde Yenilikler ve Uygulamaları Sempozyumu, Kayseri, Turkey 2010, p. 95.

[7] O. Dogmus, A. Onat, Ş. Yılmaz, Ş. Ergün Ksü, Fen Ve Mühendislik Dergisi 8, 53 (2005).

[8] I. Ekmekci, A.T. Inan, H. Oner, A. Onat, EEST Part A 29, 1431 (2012).

[9] T. Sisman, M.Sc. Thesis, University of Marmara, Turkey (2013).

[10] A.T. Inan, Ph.D. Thesis, University of Marmara, Istanbul, Turkey (2002).

[11] G. Chawla, M.S. Sachdev, G. Ramakrishna, in: India Conference, INDICON 2008 Annual IEEE, IEEE 2008, p. 234. 